\title{
Controlled Surface Modification of CNTs using Mild Acids through Powerful Sonication Technique
}

\author{
D.S. AHMED ${ }^{a, *}$ AND A.L. ABED ${ }^{b}$ \\ ${ }^{a}$ Applied Science Department, University of Technology, Baghdad, Iraq \\ ${ }^{b}$ Nanotechnology and Advanced Materials Research Center, University of Technology, Baghdad, Iraq \\ Aqueous acid solution of the mixture of $8 \mathrm{MHNO}_{3} / 8 \mathrm{MH}_{2} \mathrm{SO}_{4}$ with ratio of $1: 2$ was used to modify multiwall \\ carbon nanotubes, using powerful sonication of the nanotubes in ultrasonication bath for $8 \mathrm{~h}$ at room temperature \\ to generate functional groups and to minimize the structural damage of the multiwall carbon nanotubes during \\ the reactions. Structural and morphological characterization of samples was carried out using Fourier transform \\ infrared spectroscopy, X-ray diffraction and the transmission electron microscopy to confirm the effectiveness of \\ the functionalization method and to confirm the formation of functional groups, such as $\mathrm{C}=\mathrm{O}$ and $\mathrm{COOH}$, on the \\ surface of MWCNTs.
}

DOI: 10.12693/APhysPolA.134.7

PACS/topics: modification of MWCNTs, aqueous acid solution, functional groups

\section{Introduction}

Depending on the process of fabrication of carbon nanotubes (CNTs), there are two types of CNTs: singlewalled carbon nanotubes (SWCNTs) and multi-walled carbon nanotubes (MWCNTs) [1-4]. CNTs are novel nanomaterials that have exceptional optical, electronic, thermal [5], chemical [6], and mechanical [7] characteristics, resulting from their exceptional chemical structure and size [8].

The interest in CNTs is gradually increasing because of their unique properties associated with electric conduction and chemical affinity for different chemical compounds [9]. CNTs have an enormous commercial potential in different applications involving composites, biosensors, biomedical, electrochemical and field emitting devices, supercapacitors and applications of pharmaceutical filed $[10,11]$.

To make CNTs useful in these applications, it is required to solve the excessive hydrophobicity of CNTs, which leads to aggregates in polar fluids [12, 13]. To change the hydrophobic state of CNTs, their surfaces are frequently modified via covalent or noncovalent functionalization process to form a hydrophilic state.

Covalent surface functionalization includes incorporation of functional groups into the external side walls of CNTs [14]. In contrast, the noncovalent surface modification is based on Van der Waals and $\pi-\pi$ stacking interactions between the functional molecules and the large $\pi$-system of the CNTs. If those interactions are sufficiently strong, CNTs can be simply de-bundled and returned to the hydrophilic state using ultrasonication method [15].

*corresponding author; e-mail: duhasaadi2015@gmail.com
Moreover, the covalent strategy depends presently on attachment of functional groups to CNTs, including acid treatment by an aqueous acid mixture. Variation of the acid type, concentration and reaction conditions (like temperature or sonication power) helps to cover CNTs by functional groups at the tips and defect points [16]. Functional groups are then used to combine different other groups for improving the solubility of CNTs [17]. The introduction takes place via carboxylic groups $\mathrm{COOH}$ during treatment with a mixture of acids.

Covalent modification offers the benefit of being stronger through manipulation and processing as compared with non-covalent dispersion. However, both covalent and non-covalent modification of CNTs have been exploited for the application of such materials in the field of drug delivery $[18,19]$.

In this work we have evaluated the effect of long period sonication on functionalized MWCNTs by aqueous acid treatment for $8 \mathrm{~h}$ to increase the dispersion in stable colloidal suspensions with less disruption. We have studied the chemical properties of raw-MWCNTs and functionalized F-MWCNTs by Fourier transform infrared spectroscopy (FTIR, 8400S, Shimadzu) and by X-ray diffraction (XRD, 6000-Shimadzu X-ray Diffractometer) to confirm the functionalization of MWCNTs. In addition, surface morphology and microstructure of raw MWCNTs and F-MWCNTs were studied using transmission electron microscopy (TEM, Philips EM208, Iran).

\section{Experimental work}

$0.5 \mathrm{~g}$ of MWCNTs were mixed with $100 \mathrm{ml}$ of aqueous acid mixture of $8 \mathrm{MHNO}_{3} / 8 \mathrm{MH}_{2} \mathrm{SO}_{4}$ with a ratio of $1: 2$. Then, the controlled surface modification of MWCNTs based on powerful sonication method was carried out by sonicating MWCNTs in ultrasonication bath for $8 \mathrm{~h}$ at room temperature to form the functional groups and to minimize the structural damages of MWCNTs during 
reactions. Subsequently, the sample was rinsed carefully with deionized water and vacuum filtered using a $0.22 \mu \mathrm{m}$ polycarbonate filter. Finally, the oxidized CNTs were dried under vacuum at $90{ }^{\circ} \mathrm{C}$ for $18 \mathrm{~h}$. Chemical analysis of raw MWCNTs and of F-MWCNTs, functionalized using powerful sonication method, was carried out using Fourier transform infrared spectroscopy (FTIR, 8400S, Shimadzu), X-ray diffraction (XRD, 6000-Shimadzu Xray Diffractometer) and by imaging in a transmission electron microscope (TEM, Philips EM208, Iran).

\section{Results and discussion}

\subsection{FTIR analysis}

FTIR spectroscopy was used to determine the functional groups of raw MWCNTs and of F-MWCNTs and to recognize the atomic arrangement and the concentrations of the present chemical bonds. Figure $1 \mathrm{a}$ and $\mathrm{b}$ shows FTIR spectra of raw MWCNTs and MWCNTs after sonication in ultrasonic bath with mild mixture for $8 \mathrm{~h}$ at room temperature, respectively.

As shown in Fig. $1 \mathrm{~b}$ the characteristic peak at $1734 \mathrm{~cm}^{-1}$ is attributed to carboxyl group $\mathrm{C}=\mathrm{O}$, which implies the introduction of functional groups into the side wall of treated MWCNTs. Besides, bands at $2924 \mathrm{~cm}^{-1}$ and $2856 \mathrm{~cm}^{-1}$ result from asymmetric and symmetric $\mathrm{CH}$ stretching. Absorption peak at $3414 \mathrm{~cm}^{-1}$ is due to $\mathrm{O}-\mathrm{H}$ stretching, indicating the presence of hydrogen bonded hydroxyl $(-\mathrm{OH})$. Moreover, absorption peak at $3414 \mathrm{~cm}^{-1}$ is related to hydroxyl group $(-\mathrm{OH})$ which implies the introduction of hydroxyl groups (attributed to $\mathrm{OH}$ stretching). On the other hand, the absorption peaks of $\mathrm{C}=\mathrm{C}$ bonds at $1635 \mathrm{~cm}^{-1}$ and $\mathrm{C}-\mathrm{C}$ bonds at $1525 \mathrm{~cm}^{-1}, 1390 \mathrm{~cm}^{-1}$ and $1163 \mathrm{~cm}^{-1}$ are due to aromatic rings of the carbon skeleton and are known as carbonyl group structure, as shown in Fig. 1b.

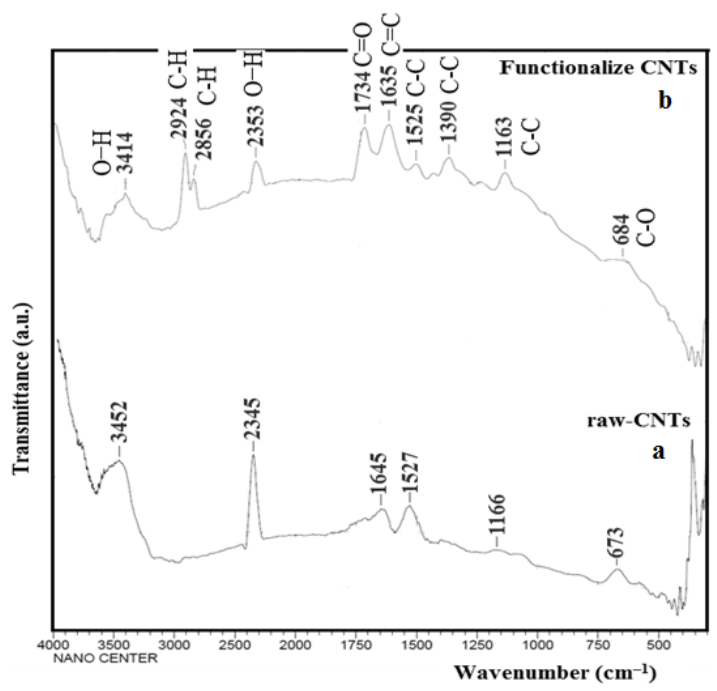

Fig. 1. FTIR analysis of (a) raw MWCNTs, (b) MWCNTs treated in a mild acid for $8 \mathrm{~h}$.

\subsection{TEM analysis of MWCNTs treated using powerful sonication method}

TEM analysis was used to determine the morphology and structural properties of MWCNTs before and after sonication for $8 \mathrm{~h}$. Results are shown in Fig. 2a and b, respectively. Figure $2 \mathrm{~b}$ shows MWCNTs functionalized by treatment with mild acid mixture. It reveals debundled MWCNTs with small diameter ranging between 15-20 nm. No MWCNTs agglomeration was observed in this sample as compared with raw MWCNTs, before the treatment with mild acid mixture (see Fig. 2a). Figure $2 \mathrm{a}$ shows agglomeration of raw MWCNTs with large diameter (more than $40 \mathrm{~nm}$ ).
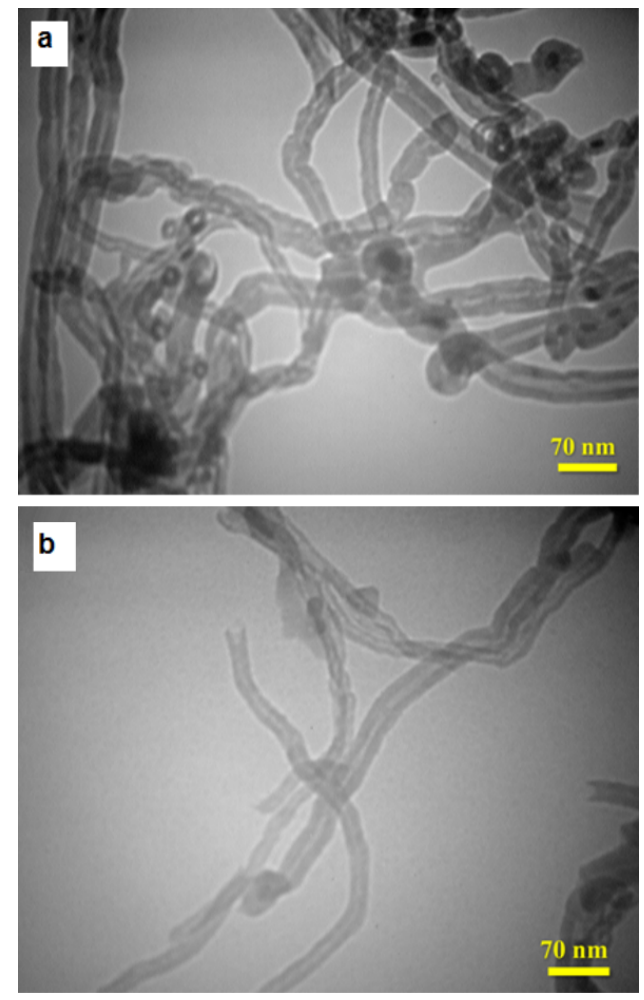

Fig. 2. TEM micrograph of MWCNTs (a) before treatment and (b) after treatment in a mild acid for a period of $8 \mathrm{~h}$.

Sonication in mild acid mixtures for $8 \mathrm{~h}$ leads to cutting of the highly tangled long MWCNTs into shorter pieces and formation of carboxylic groups $(\mathrm{COOH})$ at the open ends. There is no structural damage of CNTs at applied power of sonication.

These results reveal that ultasonication using a mild acid for a period of $8 \mathrm{~h}$ is efficient and does not result in a large damage to the structure of nanotubes, while it is suitable enough to generate functional groups during the functionalization process.

Figure $3 \mathrm{a}$ and $\mathrm{b}$ shows XRD patterns of raw and treated MWCNTs with $2 \theta=25.1^{\circ}$ and $2 \theta=25.3^{\circ}$ corresponding to reflection planes (002). 

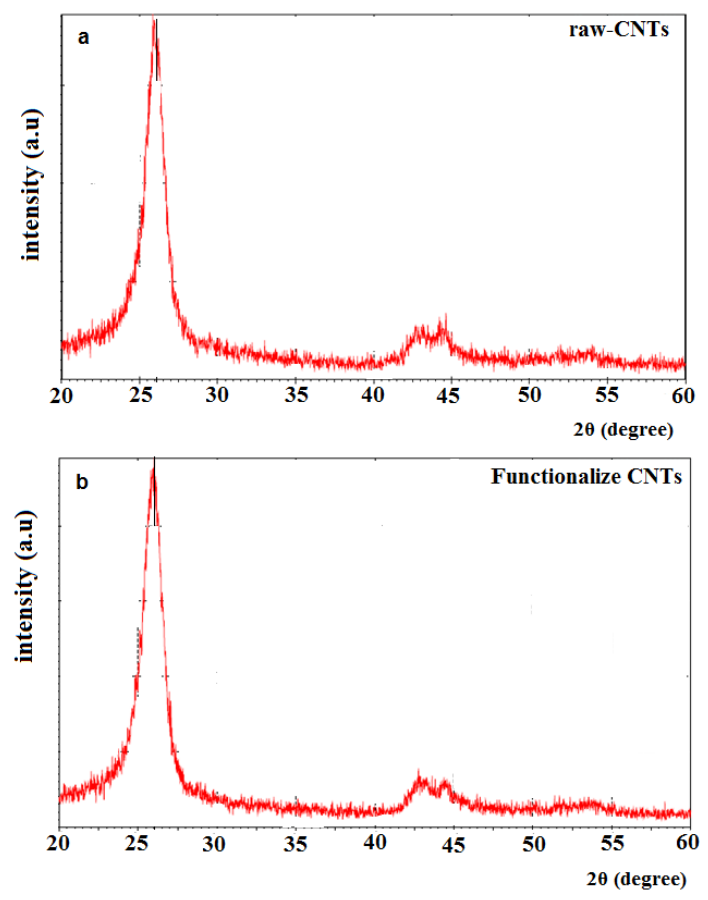

Fig. 3. XRD patterns of (a) raw MWCNTs and (b) treated MWCNTs.

\section{Conclusions}

In the present work, the purpose of surface functionalization of MWCNTs using aqueous acid solution of mixtures $8 \mathrm{MHNO}_{3} / 8 \mathrm{MH}_{2} \mathrm{SO}_{4}$ with ratio $(1: 2)$ was to minimize the structural damage of MWCNTs and to study the effect of powerful sonication after treatment for $8 \mathrm{~h}$ at room temperature. Treatment has resulted in an improvement of introduction of functional groups into the surface of acid-treated MWCNTs, as shown by FTIR, $\mathrm{XRD}$ and SEM analysis.

\section{Acknowledgments}

The authors are thankful to the Center of Nanotechnology and Advanced Materials, University of Technology, Baghdad, Iraq for their help with performing the TEM, FTIR and XRD analysis.

\section{References}

[1] C. Klumpp, K. Kostarelos, M. Prato, A. Bianco, Biochim. Biophys. Acta 1758, 404 (2006).

[2] L. Zhao, H. Liu, N. Hu, J. Colloid Interface Sci. 296(1), 204 (2006).

[3] Q. Mu, W. Liu, Y. Xing, H. Zhou, Z. Li, Y. Zhang, L. Ji, F. Wang, Z. Si, B. Zhang, B. Yan, J. Phys. Chem. C 112(9), 3300 (2008).

[4] J. Kathi, K.Y. Rhee, J. Mater. Sci. 43, 33 (2008).

[5] I.D. Şimăndan, M. Popescu., A.Lórinczi, A. Velea, E. Fagadar-Cosma, Digest J. Nanomat. Biostruct. 5(4), 1029 (2010).

[6] V.M. Sivakumar, A.Z. Abdullah, A.R. Mohamed, S.P. Chai, Digest J. Nanomat. Biostruct. 5(3), 691 (2010).

[7] S.M. Ghoreishi, M. Behpour, M. Khayatkashani, M.H. Motaghedifard, Digest J. Nanomat. Biostruct. 6(2), 625 (2011).

[8] D. Dima, M. Murarescu, G. Andrei, Digest J. Nanomat. Biostruct. 5(4), 1009 (2010).

[9] H. Chung, Y. Son, T.K. Yoon, S. Kim, W. Kim, Ecotoxicology and Environmental Safety 74, 569 (2011).

[10] Z. Spitalsky, D. Tasis, K. Papagelis, C. Galiotis, Prog. Polym. Sci. 35(3), 357 (2010).

[11] Y. Zhang, Y. Bai, B. Yan, Drug Discovery Today 15, 428 (2010).

[12] L. Vaisman, G. Marom, H.D. Wagner, Adv. Funct. Mater. 16, 357 (2006).

[13] O. Breuer, U. Sundararaj, Polym. Compos. 25, 630 (2004).

[14] K.A. Wepasnick, B.A. Smith, J.L. Bitter, D.H. Fairbrother, Anal. Bioanal. Chem. 396(3), 1003 (2010).

[15] W. Zhao, C. Song, P.E. Pehrsson, J. Am. Chem. Soc. 124(42), 12418 (2002).

[16] K.J. Ziegler, Z. Gu, H. Peng, E.L. Flor, R.H. Hauge, R.E. Smalley, J. Am. Chem. Soc. 127(5), 1541 (2005).

[17] D.S. Ahmed, A.J. Haider, M.R. Mohammad, Energy Procedia 36, 1111 (2013).

[18] A. Aqel, K.M.M. Abou El-Nour, R.A.A. Ammar, A. Al-Warthan, Arabian Journal of Chemistry 5, 1 (2012).

[19] Z. Konya, I. Vesselenyi, K. Niesz, A. Kukovecz, et al., Chem. Phys. Lett. 360(5), 429 (2002). 